\title{
AVALIAÇÃO DO GERENCIAMENTO DOS RESÍDUOS SÓLIDOS DE FUNDIÇÃO COM BASE NA PRODUÇÃO MAIS LIMPA
}

\section{VALUATION OF THE MANAGEMENT FOUNDRY SOLID RESIDUES BASED ON THE CLEANER PRODUCTION}

\author{
Adriana Gresielly Fabrini Diniz ${ }^{1}$; Ivanir Luis de Oliveira ${ }^{2}$ \\ ${ }^{1}$ Federal Technological University of Paraná - UTFPR - Ponta Grossa - Brasil \\ adri.diniz@yahoo.com.br \\ ${ }^{2}$ Federal Technological University of Paraná - UTFPR - Ponta Grossa - Brasil \\ ivanir@pesquisador.cnpq.br
}

\begin{abstract}
Resumo
A indústria de reciclagem de alumínio tem se expandido exigindo das ferramentas gerenciais adaptações a este novo segmento de mercado. Na etapa de fundição, o gerenciamento das matérias-primas é fundamental para a sustentabilidade deste setor, alguns aspectos críticos estão relacionados à logística, disponibilidade, custos e qualidade das fontes secundárias de alumínio. Este gerenciamento está relacionado com a produtividade e rentabilidade do processo de fundição, pois influencia diretamente nas perdas de processo. Através do levantamento de informações sobre o processo produtivo de uma empresa, de pequeno porte, do ramo de fundição de alumínio secundário, foram levantados dados que auxiliaram na determinação do atual cenário organizacional em termos de produtividade, custos e geração de resíduos sólidos. Com base no conceito da Produção mais Limpa, analisou-se o uso de matérias-primas e as possibilidades técnicas e financeiras de migração para ações mais complexas visando elevação da eficiência do processo.
\end{abstract}

Palavras-chave: fundição de alumínio secundário, produção mais limpa, resíduos sólidos, custo de processamento.

\section{Introdução}

A partir dos anos 90, com a globalização alcançando seu pico e as inovações tecnológicas em franca expansão, houve uma elevação, por parte das empresas, na consciência ambiental, o que permitiu o aperfeiçoamento e desenvolvimento de normas e ferramentas de gestão ambiental, destacam-se a ISO (International Organization for Standardization) 14.000, Avaliações do Ciclo de Vida, Produção Limpa (PL), Produção mais Limpa (PmaisL), Ecologia Industrial, Zero Emission Research Iniciative - Zeri, entre outros,

Porém, não se pode negar que a falta de conhecimento, recursos ou consciência, muitas vezes excluem empresas de agregarem às suas rotinas iniciativas e ações voltadas à preservação e sustentabilidade ambiental. Para estes casos, foram desenvolvidos artifícios, como legislações, 
tratados, acordos e convenções nacionais ou internacionalmente fixadas, a fim de pressionar as empresas a buscarem formas de minimização dos impactos ambientais causados por seus processos produtivos. Estes artifícios também se perpetuaram mais rapidamente a partir dos anos 90, principalmente após a Conferência das Nações Unidas sobre o Meio Ambiente realizado no Brasil, na cidade do Rio de Janeiro em 1992. Em contrapartida, algumas organizações tratam as questões ambientais como diferencial competitivo e agregação de valor aos seus produtos ou serviços.

Estratégias de gerenciamento ambiental agregam valor aos produtos, pois elevam a produtividade das organizações através da otimização do processo produtivo, desenvolvimento de produtos ambientalmente sustentáveis ou com matérias-primas recicladas e a redução, eliminação ou reaproveitamento dos resíduos gerados.

A produção de alumínio a partir de fontes secundárias opera com custos elevados devido a fatores como: logística, disponibilidade, custos e qualidade das matérias-primas. Onde os produtos concorrem diretamente com grandes grupos produtores de alumínio primário. Isto poderia explica os atuais níveis de reciclagem de aproximadamente 37\% no Brasil. (ABAL, 2004, a).

A dificuldade para os pequenos produtores é ainda maior, pois são dependentes de fornecedores, na maioria dos casos, sem o preparo adequado para atendimento das necessidades de qualidade e quantidades de matérias-primas.

Para a alteração deste cenário, são necessárias pesquisas tecnológicas e gerenciais que apontem para elevação da rentabilidade e sustentabilidade do processo.

Neste sentido, esta pesquisa analisou o processo de gerenciamento dos resíduos sólidos em uma indústria de fundição de alumínio secundário de pequeno porte, na sua fase de transformação térmica utilizando-se da ferramenta universalmente conhecida como Produção mais Lima - PmaisL

\section{Produção mais Limpa}

A PmaisL pode ser implantada pelas organizações como estratégia gerencial que permite obter crescimento econômico ao mesmo tempo em que são gerenciados os impactos ambientalmente negativos oriundos do processo produtivo. Esta afirmação é derivada do conceito da PmaisL lançada pela United Nation Environmental Program - UNEP em 1989.

Segundo a UNIDO (2004), a PmaisL pode ser utilizada em todos os processos produtivos para uso eficaz das matérias-primas, água e energia, consequentemente maximiza-se a produtividade organizacional e minimizam-se as emissões sólidas, líquidas e gasosas garantindo a sustentabilidade do processo produtivo.

O conceito de PmaisL pode ser definido da seguinte forma:

A Produção mais Limpa é a aplicação contínua de uma estratégia ambiental preventiva integrada, aplicada aos processos, produtos e serviços para aumentar a eco-eficiência e reduzir os riscos para os seres humanos e o ambiente.

Aplica-se a: 
- Processos de produção: conservação de matéria-prima e energia, eliminação matériasprimas tóxicas e redução da quantidade e toxidade de todos os resíduos e emissões;

- Produtos: redução dos impactos negativos ao longo do ciclo de vida dos produtos, desde a extração das matérias-primas até a disposição final;

- Serviços: incorporação dos conceitos ambientais no projeto e na distribuição dos serviços.

A Produção mais Limpa requer mudança de atitudes, gestão ambiental responsável, criação de políticas nacionais orientadas para o meio ambiente, e avaliação de opções tecnológicas. (apud MARINHO, 2001, p.43)

Para Diaz e Pires (2005), “a Produção mais Limpa objetiva preservar o meio ambiente, o consumidor e a comunidade, ao mesmo tempo em que busca o crescimento sustentável das organizações através da melhoria de sua eficiência, lucratividade e competitividade".

A PmaisL não é uma ferramenta a ser implantada, mas uma meta a ser atingida utilizando-se de ações como: melhoria no processo produtivo, substituição de matérias-primas, investimentos em tecnologias limpas, redesenho de produtos, reciclagem de resíduos. Para tanto, utiliza-se como base metodologias gerenciais amplamente difundidas como: Manutenção Preventiva Total - TPM, 5S, Kaisen, Gerenciamento da Qualidade Total - TQM, housekeeping, entre outros.

Para Elias e Guimarães (2003) "a Produção mais Limpa é uma prática completa em termos de opção para otimização dos processos produtivos e melhoria contínua dos mesmos, pois englobam os pontos que levam a esse fim, como: qualidade, planejamento, segurança, meio ambiente, design, saúde ocupacional e eficiência".

Não há uma metodologia única para implementação da PmaisL. O Centro Nacional de Tecnologias Limpas - CNTL (2003), propõe uma seqüência de etapas a serem cumpridas na implementação da PmaisL, conforme Tabela 1.

Tabela 1 - Etapas para implementação da PmaisL - CNTL

\begin{tabular}{|c|c|}
\hline Etapas & Atividades \\
\hline Planejamento e Organização & $\begin{array}{l}\text { - Obter comprometimento e envolvimento da alta } \\
\text { direção; } \\
\text { - Estabelecer a equipe do projeto; } \\
\text { - Estabelecer a abrangência da PmaisL e; } \\
\text { - Identificar barreiras e soluções. }\end{array}$ \\
\hline Pré-Avaliação e Diagnóstico & $\begin{array}{l}\text { - Desenvolver o fluxograma do processo; } \\
\text { - Avaliar as entradas e saídas e; } \\
\text { - Selecionar o foco da avaliação da PmaisL. }\end{array}$ \\
\hline Avaliação de PmaisL & $\begin{array}{l}\text { - Originar um balanço material e de energia; } \\
\text { - Conduzir uma avaliação de PmaisL; } \\
\text { - Gerar opções de PmaisL e; } \\
\text { - Selecionar opções de PmaisL. }\end{array}$ \\
\hline $\begin{array}{l}\text { Estudo de Viabilidade Técnica, Econômica e } \\
\text { Ambiental }\end{array}$ & $\begin{array}{l}\text { - Avaliação preliminar; } \\
\text { - Avaliação técnica; } \\
\text { - Avaliação econômica; } \\
\text { - Avaliação ambiental e; } \\
\text { - Selecionar as opções a serem implementadas. }\end{array}$ \\
\hline $\begin{array}{l}\text { Implementação de Plano de Opções e Plano de } \\
\text { Continuidade }\end{array}$ & $\begin{array}{l}\text { - Preparar plano de implementação de PmaisL; } \\
\text { - Implementação das opções de PmaisL; } \\
\text { - Monitorar e avaliar e; } \\
\text { - Sustentar atividades de PmaisL. }\end{array}$ \\
\hline
\end{tabular}


O Conselho Empresarial Brasileiro para o Desenvolvimento Sustentável - CEBDS (2002) sugere outra metodologia em seu Guia de PmaisL, conforme Tabela 2.

Tabela 2 - Etapas para implementação da PmaisL - CEBDS

\begin{tabular}{l}
\hline Comprometimento da direção da empresa \\
\hline Sensibilização dos funcionários \\
\hline Formação do Ecotime \\
\hline Apresentação da metodologia \\
\hline Pré-avaliação \\
\hline Elaboração de fluxogramas \\
\hline Tabelas quantitativas \\
\hline Definição de indicadores \\
\hline Avaliação dos dados coletados \\
\hline Barreiras \\
\hline Seleção do foco de avaliação e priorização \\
\hline Balanços de massa e de energia \\
\hline Avaliação das causas de geração de resíduos \\
\hline Geração de opção de PmaisL \\
\hline Avaliação técnica, ambiental e econômica \\
\hline Seleção de opções \\
\hline Plano de monitoramento e continuidade \\
\hline
\end{tabular}

Segundo UNIDO/UNEP, as ações a serem tomadas para implementação da PmaisL estão na Tabela 3 (apud LEMOS, 1998).

Tabela 3 - Etapas para implementação da PmaisL - UNIDO/UNEP

\begin{tabular}{l}
\hline $\begin{array}{c}\text { Tomada de decisão, por parte dos gestores, de que uma ação precisar ser } \\
\text { empreendida }\end{array}$ \\
\hline Formação da equipe de projeto \\
\hline Discussão do programa com os trabalhadores e supervisores \\
\hline Documentação dos principais processos a serem estudados \\
\hline Planejamento e organização \\
\hline Pré-avaliação \\
\hline Avaliação \\
\hline Estudo de Viabilidade \\
\hline Implementação
\end{tabular}

Apesar de diferenças entre as três abordagens, identifica-se que semelhanças quanto a análise das oportunidades de aprimoramento. Neste caso, o processo produtivo é analisado segundo a redução ou reutilização dos resíduos de produção. A Figura 1 estabelece o fluxograma de ações que podem ser implantadas pelas empresas no processo de gerenciamento da produção. 
Figura 1 - Oportunidades de PmaisL

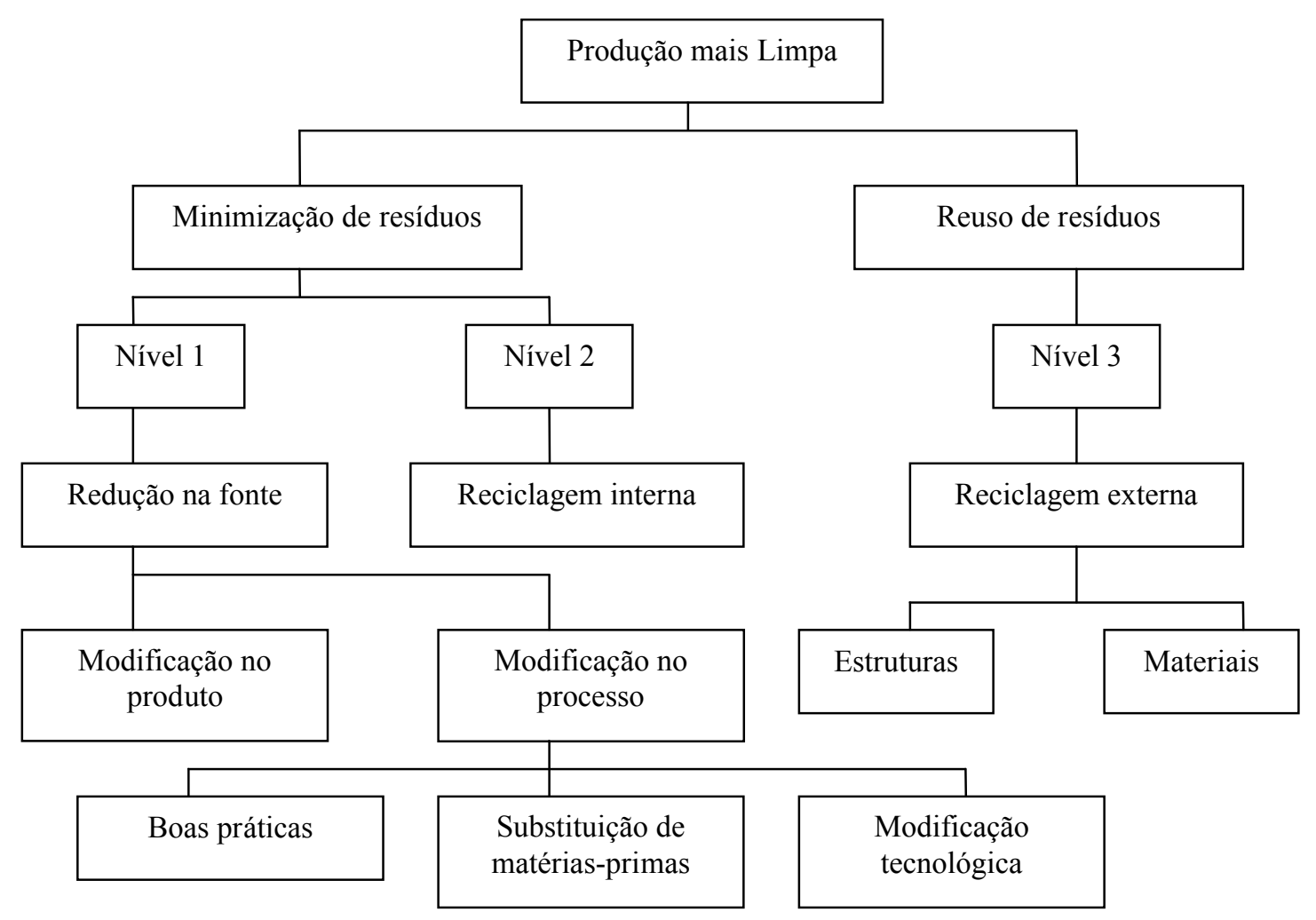

O nível 1 de PmaisL, é o que inclui ações mais complexas objetivando minimizar as emissões sólidas, líquidas e gasosas do processo produtivo na fonte. Este nível inclui ações que vão desde modificações no produto até alterações do processo. Para tanto, podem ser utilizadas técnicas de boas praticas de fabricação, substituição de matérias-primas e modificações tecnológicas. (CNTL, 2003).

O nível 2 também é composto por ações complexas e objetiva a minimização de resíduos através da reciclagem interna, ou seja, todo resíduos oriundo do processo produtivo é reprocessado internamente. Ou no processo produtivo já existente ou como matéria-prima para novos produtos dentro da própria empresa. (CNTL, 2003)

E o nível 3 apresenta a oportunidade de reuso dos resíduos através da reciclagem externa. Neste nível, os materiais são comercializados para terceiros que os reciclarão ou os utilizarão como matérias-primas para novos produtos. (CNTL, 2003)

Estes três níveis de PmaisL norteiam as empresas que objetivam reutilizar ou minimizar a geração de resíduos sólidos de seus processos. Cabendo análises econômicas, financeiras e ambientais entorno de cada uma delas a fim de identificar em que nível a empresa se encontra e as ações que devem ser tomadas para se alcançar níveis mais elevados de eficiência do processo. (CNTL, 2003) 


\section{Local de pesquisa}

A pesquisa foi realizada numa empresa de base tecnológica no ramo de fundição de alumínio secundário atualmente incubada na Universidade Tecnológica Federal do Paraná/Unidade de Ponta Grossa. O local foi escolhido devido ao cunho tecnológico empregado no processo produtivo. E pelo fato de operar com estoque zero, o que garante uma melhor tomada e análise dos resultados com base no monitoramento de entradas e saídas do processo.

A facilidade na disponibilidade dos dados coletados, tanto de produção quanto financeiros, foi decisiva na escolha do local de pesquisa. Outro fator importante foi a qualidade dos dados tendo em vista o equipamento de fusão utiliza tecnologia moderna capaz de fornecer informações seguras e completas de cada lote produzido. Estes fatores foram determinantes na escolha do local da pesquisa por fornecer informações relevantes ao setor de fundição.

Com isto, foi possível levantar importantes informações como a produtividade, rentabilidade, a eficiência do processo e a influência da sazonalidade, dos tipos de matérias-primas e dos procedimentos de produção sobre esses fatores.

\section{Detalhamento do processo}

A Figura 2, representa o fluxo das matérias-primas do processo produtivo utilizado para obtenção da liga ASTM B319.1 foco desta pesquisa.

Figura 2 - Fluxograma do processo

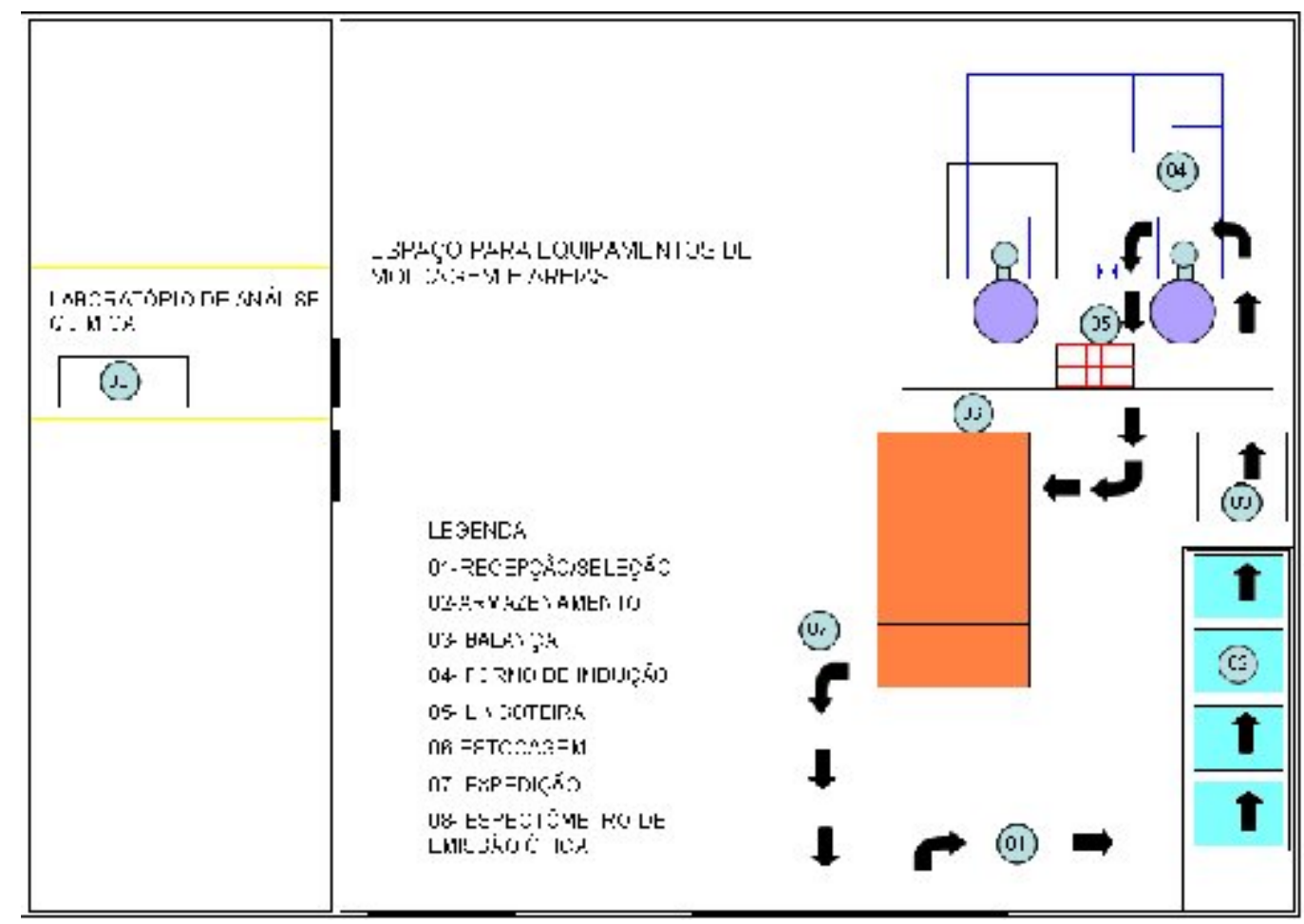

Após a chegada das matérias-primas na empresa, a primeira ação a ser tomada é o recebimento através de formulário onde são preenchidos dados como: nome do fornecedor, data, 
tipos de matéria-prima e quantidade. Este formulário é utilizado para controle dos estoques.

Concomitantemente ao recebimento é procedida a pesagem dos materiais a fim de efetuar o pagamento dos fornecedores. Efetua-se então a separação dos materiais através de suas propriedades físicas, químicas e mecânicas, este procedimento exclui os materiais inapropriados para o processo produtivo. Os materiais são então armazenados em local apropriado para que não ocorram misturas entre os materiais ou contaminação dos mesmos. Conforme Figura 3.

Figura 3 - Armazenagem das matérias-primas

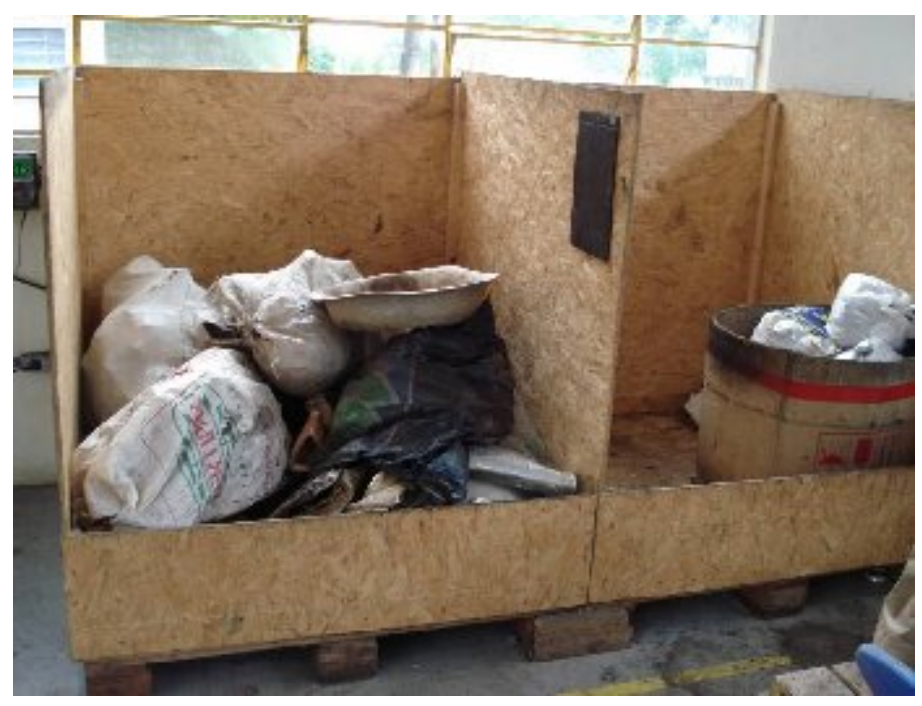

As matérias-primas ficam armazenadas até a definição da liga a ser produzida, a partir deste momento, uma ordem de fabricação é emitida, nela contam as quantidades necessárias de matériasprimas para cada corrida produtiva. Com este documento em mãos, procede-se uma nova pesagem dos materiais que comporão a carga de fundição. A Figura 4 apresenta o momento da pesagem das matérias-primas que alimentarão o forno de fundição.

Figura 4 - Pesagem das matérias-primas

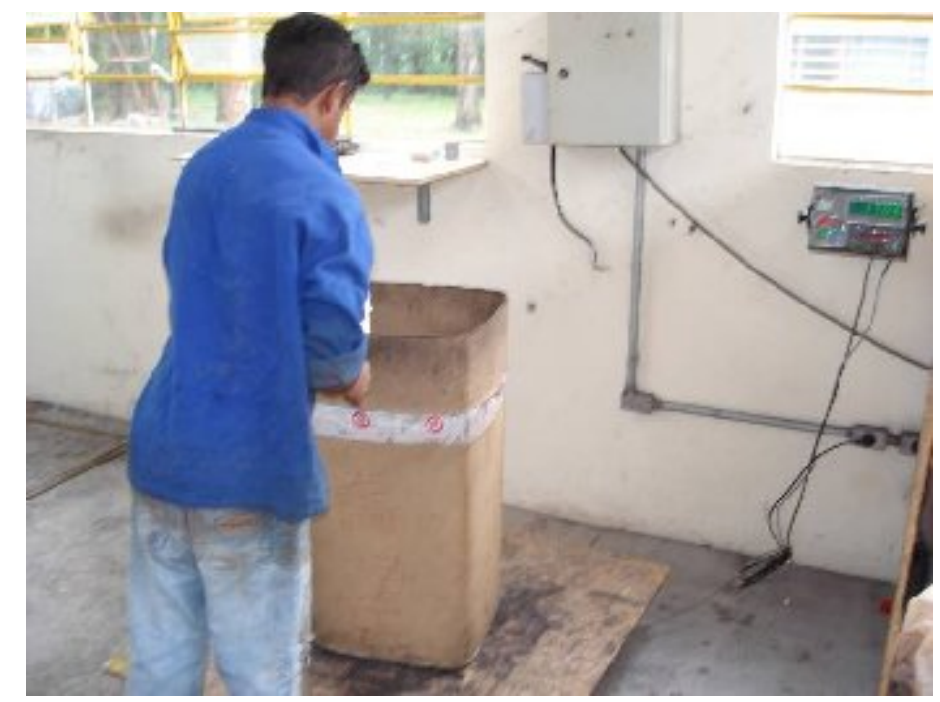


Seguindo um procedimento pré-estabelecido pela empresa os materiais são introduzindo no forno para serem fundidos. A Figura 5 apresenta este procedimento.

Figura 5 - Procedimento de alimentação do forno de fusão

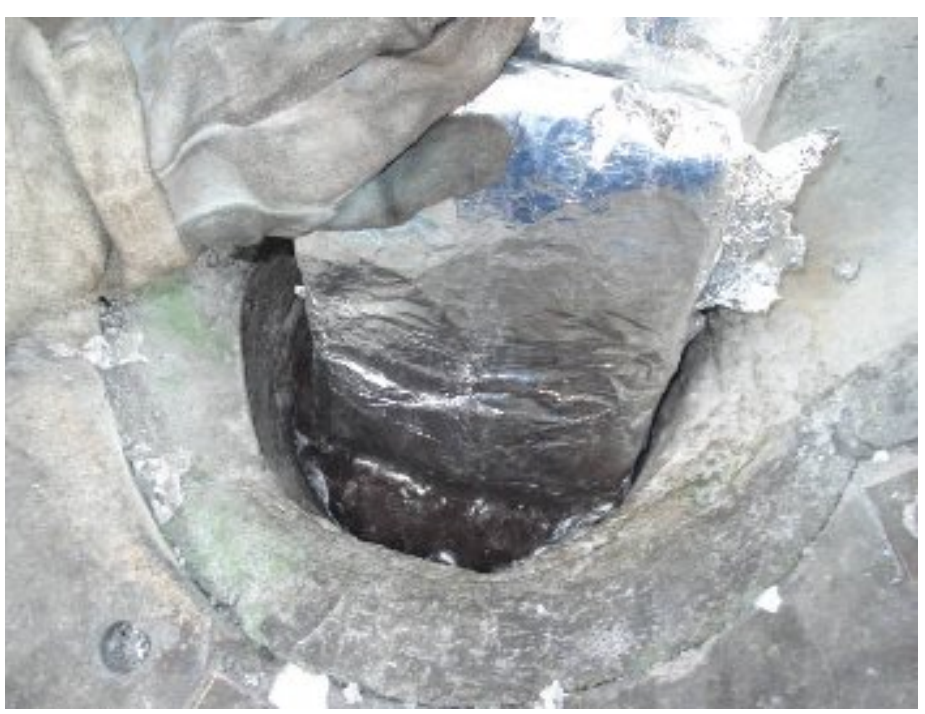

Após o abastecimento do forno e completa fusão dos materiais, retira-se uma pequena amostra do metal líquido (Figura 6 e Figura 7) que será submetido à análise para verificação da composição química da amostra.

Figura 6 - Extração de amostra para análise

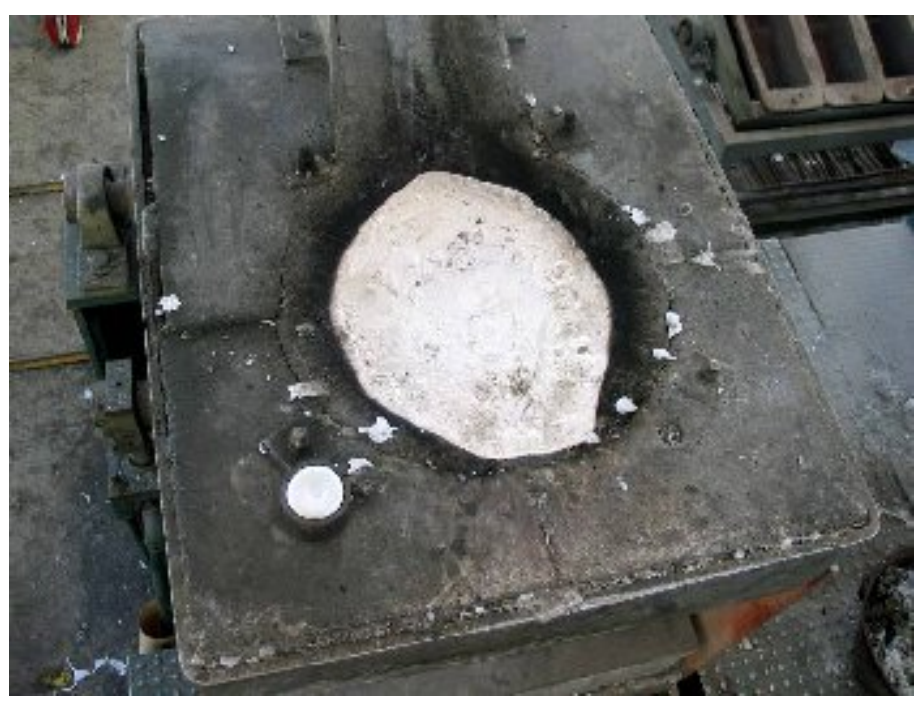




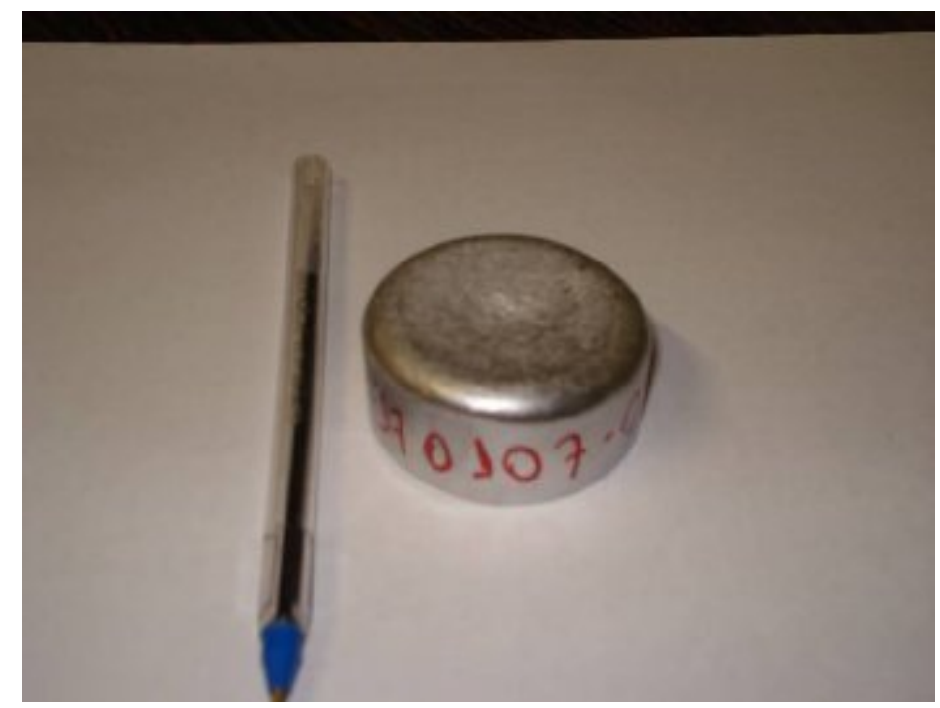

O equipamento (Figura 8) efetua a análise (Figura 9) da amostra e envia o resultado ao computador que o confronta com as propriedades químicas requeridas pela norma e informa a necessidade de correção da liga em processamento.

Figura 8 - Procedimento de análise

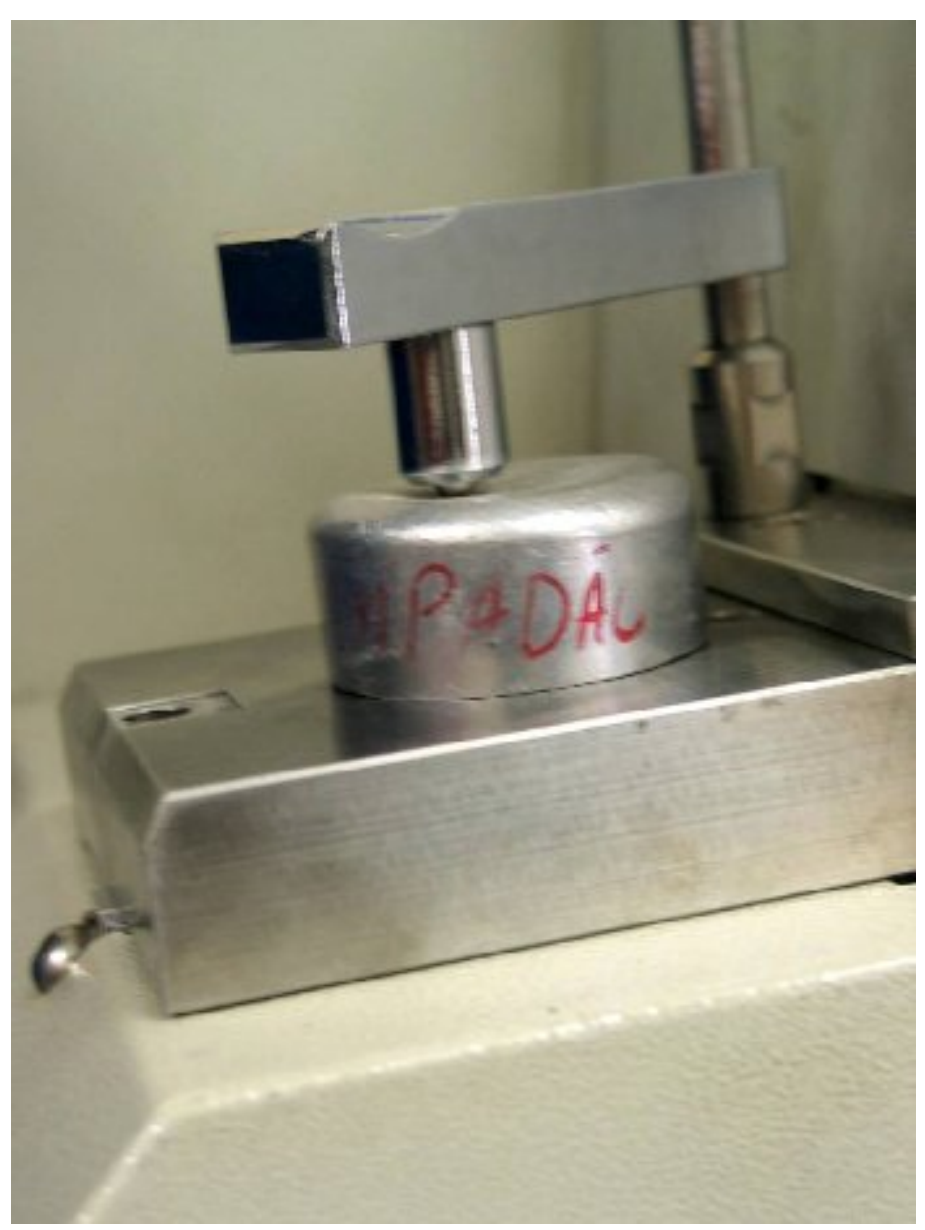


Caso ocorra a necessidade de correção, há uma planilha denominada "composição de carga", onde indica a quantidade de matéria-prima que deverá ser acrescida ao metal líquido. Após este procedimento, uma nova amostra é retirada para análise, em caso de aprovação, procede-se a escorificação e lingotamento do metal líquido (Figura 9).

Figura 9 - Lingotamento do metal líquido

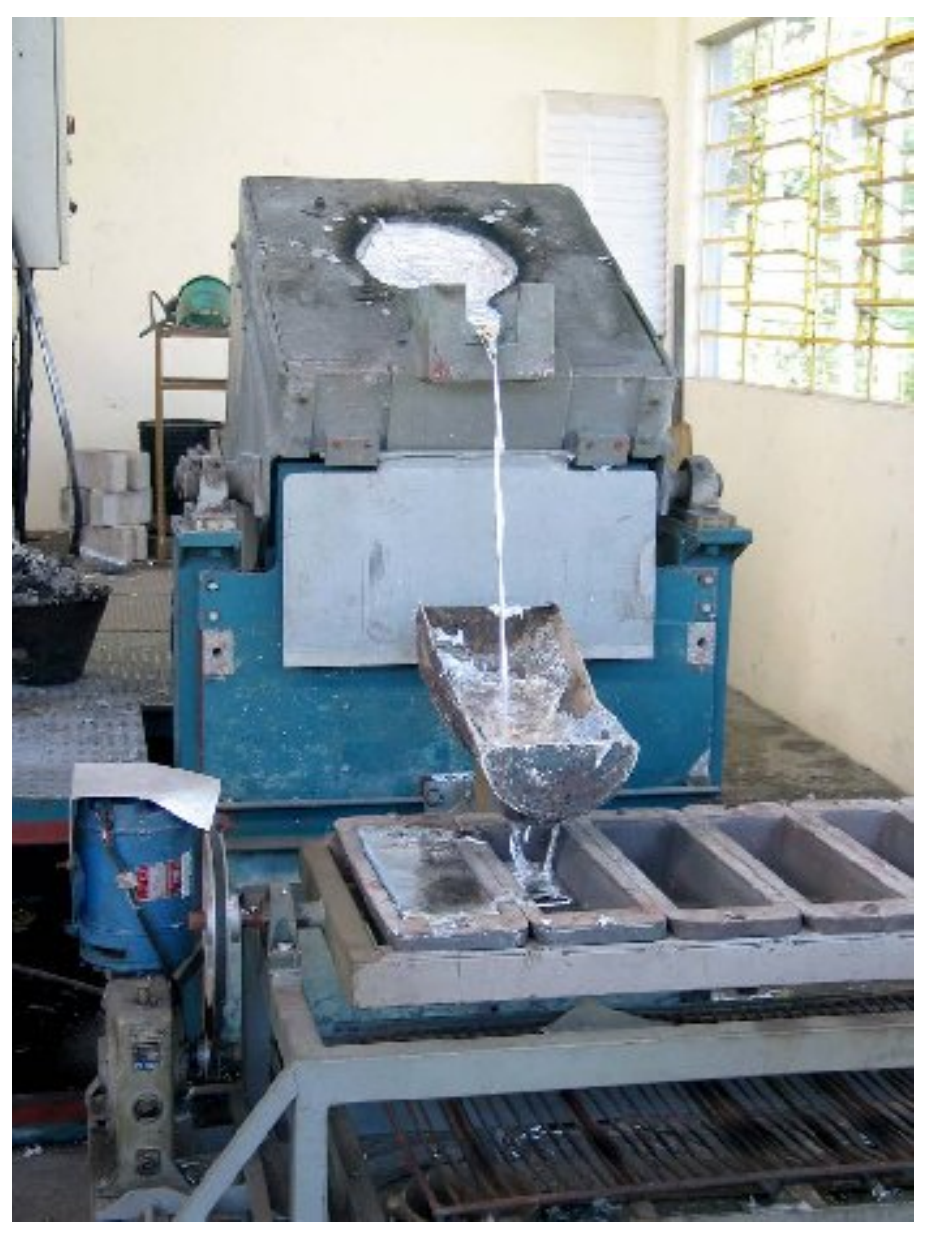

Aguarda-se o resfriamento dos lingotes (Figura 10), que são pesados e estocados para posterior entrega da produção aos clientes. 


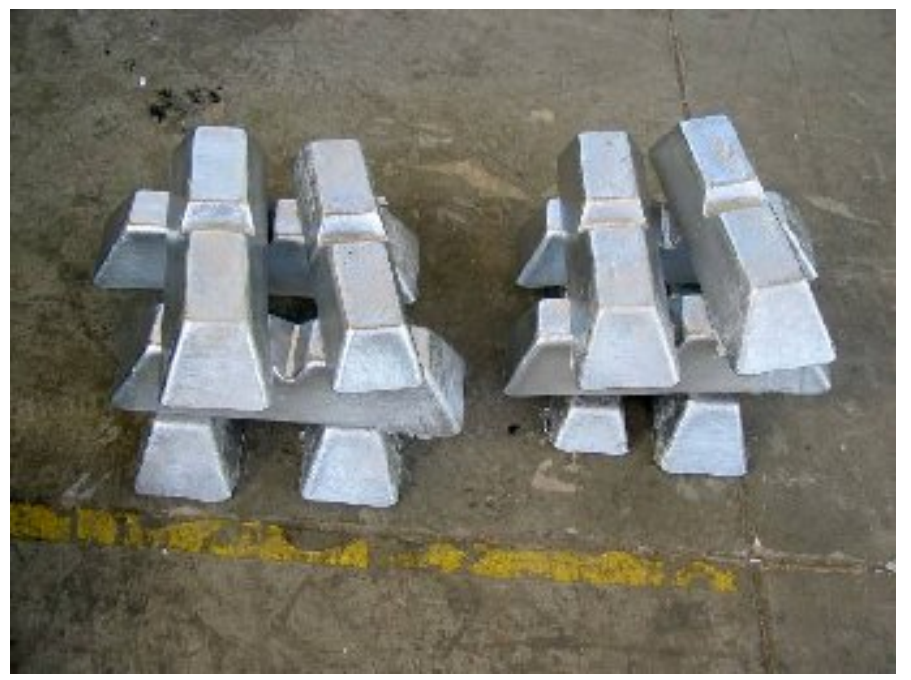

\section{Análise de entradas e saídas de materiais}

A Tabela 4 apresenta o fluxograma qualitativo global onde são representados os principais insumos, o processo de produção da liga secundária ASTM B319.1 e as saídas oriundas do mesmo.

Tabela 4 - Fluxograma qualitativo de entradas e saídas do processo produtivo da liga secundária - ASTM B319.1

\begin{tabular}{|c|c|c|}
\hline Entradas & Processo & Saídas \\
\hline $\begin{array}{l}\text { Pistão } \\
\text { Panela } \\
\text { Cabeçote } \\
\text { Laminado } \\
\text { Perfil } \\
\text { Cabo } \\
\text { Lata } \\
\text { Material de Refusão } \\
\text { Alumínio Mole } \\
\text { Alumínio Duro } \\
\text { Placa } \\
\text { Magnésio } \\
\text { Silício } \\
\text { Cobre } \\
\text { Fluxo } \\
\text { Energia elétrica }\end{array}$ & Fundição & $\begin{array}{l}\text { Escória de fundição } \\
\text { Efluentes líquidos } \\
\text { Emissões gasosas } \\
\text { Material refratário } \\
\text { Matérias-primas refugadas } \\
\text { Ligas fora de especificações } \\
\text { Perda de metal líquido } \\
\text { Perdas térmicas }\end{array}$ \\
\hline
\end{tabular}

A Tabela 4 demonstra os principais materiais secundários levantados a partir da disponibilidade do mercado na ocasião da pesquisa e utilizados ao longo do trabalho. Com exceção do cobre, adquirido também como sucata, os elementos de liga magnésio e silício, foram comprados de empresas especializadas. Quanto ao fluxo, utilizado na limpeza do banho também foi adquirido no mercado.

Para o processamento destas matérias-primas e obtenção dos lingotes de alumínio, foi 
utilizado forno elétrico a indução, o que justifica a presença da energia elétrica e água como insumos.

Cabe lembrar que para a obtenção de uma mesma liga podem ser utilizadas diversas composições de materiais secundários. A escolha do material que será utilizado depende da sazonalidade do mercado.

Durante a realização da pesquisa foram levantadas potenciais saídas conforme demonstradas na Tabela 4. No caso da água, sua utilização ocorreu apenas nos sistema de refrigeração e suas perdas se davam por evaporação não impactando significativamente tanto ambiental quanto financeiramente. Quanto às perdas térmicas, foi avaliada na composição dos custos de processamento. Desta forma, durante a coleta de dados apenas os resíduos sólidos foram considerados significativos.

Os dados quantitativos referentes a custos, produção, geração de resíduos sólidos e preços, foram levantados em entrevista, a fim de se traçar um perfil econômico e desta forma identificar a eficiência do processo ao longo do período compreendido pela pesquisa.

A Tabela 5 representa a matriz de dados primários de produção, onde foram detalhadas as quantidades da liga ASTM B319.1 produzidas no período pesquisado, as respectivas quantidades e percentuais de resíduos sólidos gerados, além dos custos de transporte e disposição, o preço de venda dos resíduos para reciclagem externa e a estimativa do custo unitário de processo. Para o caso do gerenciamento dos resíduos sólidos, três alternativas podem ser consideradas, reciclagem interna, externa ou disposição final. Neste sentido, levantaram-se os custos para disposição final (D) e reciclagem externa (E) por empresas licenciadas para estes serviços.

Tabela 5 - Dados primários de produção

\begin{tabular}{|c|c|c|c|c|c|c|}
\hline Meses & Produção/kg & Resíduos/kg & Resíduos/\% & $\begin{array}{l}\text { Custo de Transporte } \\
\text { e Disposição/R } \$ / k g\end{array}$ & $\begin{array}{l}\text { Preço de venda } \\
\text { dos resíduos/R\$ }\end{array}$ & $\begin{array}{l}\text { Custo unitário } \\
\text { de processo } / \mathrm{kg}\end{array}$ \\
\hline & $\mathbf{A}$ & B & $\mathbf{C}$ & D & $\mathbf{E}$ & Cup \\
\hline Jun/06 & 663,48 & 77,83 & 11,73 & 0,60 & 0,80 & 3,50 \\
\hline Jul/06 & 686,54 & 72,86 & 10,61 & 0,60 & 0,80 & 3,50 \\
\hline Ago/06 & 955,00 & 140,23 & 13,18 & 0,60 & 0,80 & 3,50 \\
\hline Set/06 & $1.524,26$ & 204,34 & 13,41 & 0,60 & 0,80 & 3,50 \\
\hline Out/06 & $1.442,46$ & 259,33 & 17,98 & 0,60 & 0,80 & 3,50 \\
\hline Nov/06 & $1.920,66$ & 339,61 & 17,68 & 0,60 & 0,80 & 3,50 \\
\hline Dez/06 & 436,44 & 37,22 & 8,53 & 0,60 & 0,80 & 3,50 \\
\hline $\mathrm{Jan} / 07$ & 662,94 & 62,68 & 9,45 & 0,60 & 0,80 & 3,50 \\
\hline Fev/07 & 551,3 & 87,78 & 15,92 & 0,60 & 0,80 & 3,50 \\
\hline Mar/07 & 510,44 & 121,9 & 23,88 & 0,60 & 0,80 & 3,50 \\
\hline $\mathrm{Abr} / 07$ & 400,98 & 48,9 & 11,09 & 0,60 & 0,80 & 3,50 \\
\hline
\end{tabular}


Foram levantadas também, as quantidades de matérias-primas adquiridas durante os meses pesquisados, conforme Tabela 6.

Tabela 6 - Dados primários de produção

\begin{tabular}{|c|c|c|c|c|c|c|c|c|c|c|c|c|}
\hline Materiais & $\begin{array}{c}\text { Custo } \\
\text { unitário } \\
\text { (R\$) }\end{array}$ & $\supseteqq$ & 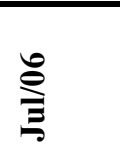 & 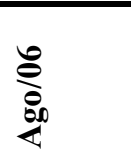 & 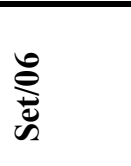 & 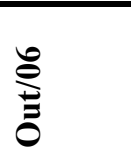 & $\frac{8}{z}$ & 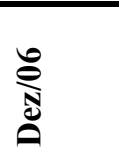 & $\stackrel{\hat{\theta}}{ٍ}$ & 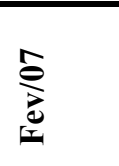 & 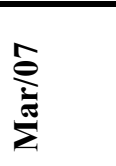 & $\stackrel{0}{e}$ \\
\hline Pistão & 3,5 & 162,68 & 120,77 & 212,94 & 247,75 & 545,44 & 134,76 & 86,9 & 0 & 0 & 0 & 0 \\
\hline Panela & 4,8 & 245,88 & 133,95 & 301,71 & 59,81 & 331,7 & 259,96 & 14,04 & 0 & 9,96 & 38,7 & 0 \\
\hline Cabeçote & 3,5 & 362,46 & 135,44 & 167,12 & 29,2 & 47,02 & 0 & 0 & 0 & 0 & 0 & 0 \\
\hline Laminado & 1,0 & 0 & 0 & 0 & 726,32 & 299,82 & 137,84 & 100,64 & 437,06 & 341,08 & 80,2 & 233,36 \\
\hline Perfil & 5,2 & 0 & 15,76 & 20,86 & 0 & 48,94 & 5,6 & 0 & 0 & 0 & 0 & 0 \\
\hline Cabo & 3,5 & 0 & 4,52 & 0 & 19,3 & 43,08 & 0 & 0 & 5,48 & 0 & 13,02 & 0 \\
\hline Lata & 3,5 & 0 & 71,11 & 154,6 & 148,55 & 354,48 & 371,92 & 22,06 & 37,16 & 55,82 & 150,84 & 60,58 \\
\hline Refusão & 0 & 0 & 246,67 & 157,31 & 130,66 & 111,4 & 157,28 & 94,98 & 87,94 & 13,75 & 146,28 & 5,68 \\
\hline Al. Mole & 4,2 & 0 & 86,84 & 136,84 & 32,8 & 147,88 & 103,3 & 40,32 & 39,68 & 56,23 & 48,48 & 35,28 \\
\hline Al. Duro & 3,5 & 13,94 & 0 & 0 & 0 & 170,78 & 862,64 & 121,52 & 97,66 & 157,56 & 178,82 & 94,2 \\
\hline Placa & 4,2 & 0 & 22,82 & 0 & 324,8 & 26,18 & 65,78 & 0 & 22,7 & 0 & 0 & 0 \\
\hline Magnésio & 11 & 0 & 0 & 0 & 0 & 0 & 0 & 0 & 0 & 0 & 0 & 0 \\
\hline Silício & 4,6 & 1,32 & 1,05 & 4,86 & 55,26 & 30,92 & 34,1 & 2,18 & 24,18 & 15,16 & 6,7 & 18,76 \\
\hline Cobre & 13 & 14,68 & 9,83 & 24,19 & 54,58 & 55,2 & 46,74 & 11,35 & 21,05 & 19,7 & 14,14 & 12,24 \\
\hline Fluxo & 2,88 & 3,92 & 2,92 & 4,8 & 7,26 & 7,6 & 2,6 & 0 & 1,2 & 0 & 0 & 0 \\
\hline \multicolumn{2}{|c|}{ Total/kg (F) } & 804,88 & 851,68 & 1185,23 & 1836,29 & 2220,44 & 2182,52 & 493,99 & 774,11 & 669,26 & 677,18 & 460,1 \\
\hline \multicolumn{2}{|c|}{ Custo Médio (Cmp) } & 4,07 & 3,77 & 4,16 & 2,95 & 3,70 & 3,78 & 3,14 & 2,27 & 2,59 & 3,38 & 2,57 \\
\hline
\end{tabular}

Objetivando identificar ações para o gerenciamento dos resíduos sólidos, foram utilizados os dados das Tabela 5 e Tabela 6 para o desenvolvimento da Tabela 7 e Tabela 8. Para a Tabela 7 calculou-se a eficiência das matérias-primas através da Equação 1.

Equação 1 - Fórmula para cálculo da eficiência das matérias-primas

$$
H=(A / F) * 100
$$

Onde;

H - Eficiência das matérias-primas (Tabela 7)

A - Produção/kg (Tabela 5)

F - Total das matérias-primas/kg (Tabela 6) 
Tabela 7 - Eficiência das matérias-primas - dados levantados

\begin{tabular}{cc}
\hline Meses & Eficiência MP \% \\
\hline & $\mathbf{H = ( A / F ) * ~ 1 0 0}$ \\
\hline Jun/06 & 82,43 \\
\hline Jul/06 & 80,61 \\
\hline Ago/06 & 89,75 \\
\hline Set/06 & 83,01 \\
\hline Out/06 & 64,96 \\
\hline Nov/06 & 88,00 \\
\hline $\mathrm{Dez} / 06$ & 88,35 \\
\hline $\mathrm{Jan} / 07$ & 85,64 \\
\hline $\mathrm{Fev} / 07$ & 82,37 \\
\hline $\mathrm{Mar} / 07$ & 75,38 \\
\hline $\mathrm{Abr} / 07$ & 87,15 \\
\hline
\end{tabular}

Na Tabela 8 avaliou-se os aspectos econômicos do processo considerando as matériasprimas, reciclagem externa, o custo de processamento e custo total de produção.

Tabela 8 - Avaliação econômica - dados levantados

\begin{tabular}{ccccc}
\hline & $\begin{array}{c}\text { Custo } \\
\text { Total de } \\
\text { MP/R\$ }\end{array}$ & $\begin{array}{c}\text { Ganho com } \\
\text { a } \\
\text { reciclagem } \\
\text { externa/R\$ }\end{array}$ & $\begin{array}{c}\text { Custo de } \\
\text { Processamento/RS }\end{array}$ & $\begin{array}{c}\text { Custo total } \\
\text { de } \\
\text { Produção/RS }\end{array}$ \\
\hline I=F*Cmp & J=B*E & Cp=Cup+Cmp & L=A*K- J \\
\hline jun/06 & 3275.86 & 62.26 & 7.57 & 4960.28 \\
\hline jul/06 & 3210.83 & 58.29 & 7.27 & 4932.86 \\
\hline ago/06 & 4930.56 & 112.18 & 7.66 & 7203.12 \\
\hline set/06 & 5417.06 & 163.47 & 6.45 & 9668.01 \\
\hline out/06 & 8215.63 & 207.46 & 7.20 & 10178.25 \\
\hline nov/06 & 8249.93 & 271.69 & 7.28 & 12210.16 \\
\hline dez/06 & 1551.13 & 29.78 & 6.64 & 2868.18 \\
\hline jan/07 & 1757.23 & 50.14 & 5.77 & 3775.02 \\
\hline fev/07 & 1733.38 & 70.22 & 6.09 & 3287.20 \\
\hline mar/07 & 2288.87 & 97.52 & 6.88 & 3414.31 \\
\hline abr/07 & 1182.46 & 39.12 & 6.07 & 2394.83 \\
\hline
\end{tabular}

Para se determinar o custo total investido pela empresa para aquisição das matérias-primas (I) nos meses pesquisados, multiplicou-se o volume total das matérias-primas compradas (F) pelo seu respectivo custo médio $(\mathrm{Cmp})$. O ganho obtido pela empresa com a comercialização dos resíduos para reciclagem externa $(\mathrm{J})$ foi calculado através da multiplicação da quantidade total de resíduos sólidos gerados pela empresa (B) pelo seu respectivo valor de venda (E).

No custo de processamento $(\mathrm{Cp})$ estão inclusos os custos médios das matérias-primas mais o custo unitário de processo (Cup). Desta forma, o custo total de produção (L) é resultado da multiplicação do volume de produção (A) pelo custo de processamento menos o ganho obtido com a reciclagem externa. 
Analisando os resultados obtidos através dos conceitos levantados no item 2 verifica-se que as ações tomadas pela empresa para gerir seus resíduos sólidos estão direcionados à reciclagem externa, para a PmaisL a empresa está classificada como pertencente ao nível 3, ou seja, a totalidade das escórias geradas são comercializadas, sem processamento, para empresa licenciada.

A partir desta verificação, novas análises foram desenvolvidas objetivando identificar a viabilidade técnica e econômica para a migração do sistema de gestão dos resíduos sólidos empregados para níveis mais complexos e desta forma obter elevação de produção e rentabilidade.

Avaliou-se a migração do nível 3 para o nível 2. Neste, as ações para o gerenciamento dos resíduos sólidos envolve maior planejamento, organização e controle, onde as emissões são recicladas ou reutilizadas dentro da própria empresa.

Para esta análise, inicialmente houve a necessidade de avaliar tecnicamente o resíduo produzido. No sentido da reutilização e empregando as mesmas técnicas de produção de ligas, realizou-se um ensaio de fusão das escórias obtendo-se um percentual de $65 \%$ do peso da mesma em alumínio metálico.

Este percentual foi utilizado como indicador para calcular o potencial de reciclagem interna e eficiência das matérias-primas conforme Tabela 9.

Tabela 9 - Eficiência das matérias-primas - nível 2

\begin{tabular}{ccc}
\hline Meses & $\begin{array}{c}\text { Reciclagem } \\
\text { interna/kg }\end{array}$ & Eficiência MP/\% \\
\hline $\mathbf{M = B * 0 , 6 5}$ & $\mathbf{N = ( ( A + M ) / F ) * 1 0 0}$ \\
\hline Jun/06 & 50.59 & 88.72 \\
\hline Jul/06 & 47.36 & 86.17 \\
\hline ago/06 & 91.15 & 88.27 \\
\hline set/06 & 132.82 & 90.24 \\
\hline out/06 & 168.56 & 72.55 \\
\hline nov/06 & 220.75 & 88.67 \\
\hline dez/06 & 24.19 & 93.25 \\
\hline Jan/07 & 40.74 & 90.90 \\
\hline Fev/07 & 57.06 & 90.90 \\
\hline mar/07 & 79.24 & 87.08 \\
\hline Abr/07 & 31.79 & 94.06 \\
\hline
\end{tabular}

Através da Talela 9 verifica-se que há possibilidades técnicas para a empresa realizar com a reciclagem interna dos resíduos sólidos uma elevação da média de eficiência das matérias-primas em aproximadamente $6,58 \%$.

Porém, o material oriundo da recuperação da escória não é um produto final, mas sim uma matéria-prima que poderá ser reintroduzida no processo. Desta forma, os custos de processamento da enésima corrida produtiva (Cp) podem ser calculados pela soma de dois componentes: custo do 
processamento da sucata (Cps) e o custo do alumínio recuperado (Calr) da escória da corrida anterior. Conforme Equação 2.

Equação 2 - Custo de processamento

$$
C p=C p s+C a l r
$$

Onde:

$$
\text { Cps }=\left[\left(C f-\mathrm{Palr}_{n}\right) R(\mathrm{Cmp}+\mathrm{Cup})\right\}
$$

Calr $=\left[\left(\right.\right.$ Palr $\left._{n}\right)(3$ Cup + Cmp $\left.)\right]$

sendo:

$$
\begin{aligned}
& \text { Palr }_{n}=C f \Psi(1-\Psi) \\
& \Psi=(1-R) R c \\
& \text { Cp }=\text { custo de processamento } \\
& \text { Cf }=\text { capacidade do forno } \\
& \mathrm{R}=\text { rendimento do processo } \\
& \text { Rc }=\text { reciclabilidade } \\
& \text { Cmp }=\text { custo das matérias-primas } / \mathrm{kg} \\
& \text { Cup }=\text { custo unitário de processo } / \mathrm{kg}
\end{aligned}
$$

Desenvolvendo a Equação 2 obtem-se a Equação 3.

Equação 3 - Relação entre custo de processamento e capacidade do forno de fundição

$$
\frac{C p}{C f}=a \Psi^{2}-a \Psi+b
$$

Sendo:

$$
\begin{aligned}
& a=[(R-1) C m p+(R-3) C u p] \\
& b=R(C m p+C u p)
\end{aligned}
$$

Para o desenvolvimento da Equação 2 e Equação 3 considerou-se máximo o rendimento de fusão dos lingotes secundários, pois seu percentual de perda é insignificante em relação às sucatas. Estudos realizados pelo Instituto de Pesquisas Tecnológicas do Estado de São Paulo - IPT objetivando avaliar o índice de produção a partir de lingotes, com uso de forno à plasma, obtiveram um percentual de 97,5\% de rendimento. (BRENDER e CRUZ, 2005).

Desta forma, a adição de lingotes secundários na composição da carga influencia diretamente nos custos de produção e na elevação da produtividade com redução da geração de 
escórias.

A influência da adição de lingotes secundários nos custos de produção está indicada no Gráfico 1 onde constam os custos de processamento $(\mathrm{Cp})$ dos níveis 3 e 2. Onde no nível 3 a escória gerada é integramente comercialização, por $\mathrm{R} \$ 0,80 / \mathrm{kg}$ para a reciclagem externa e no nível 2 é reprocessada internamente, com índice de reciclabilidade de 0,65 e compõe a carga como matériaprima de alto rendimento.

Gráfico 1 - Custo de processamento (cp) - nível 3 x nível 2

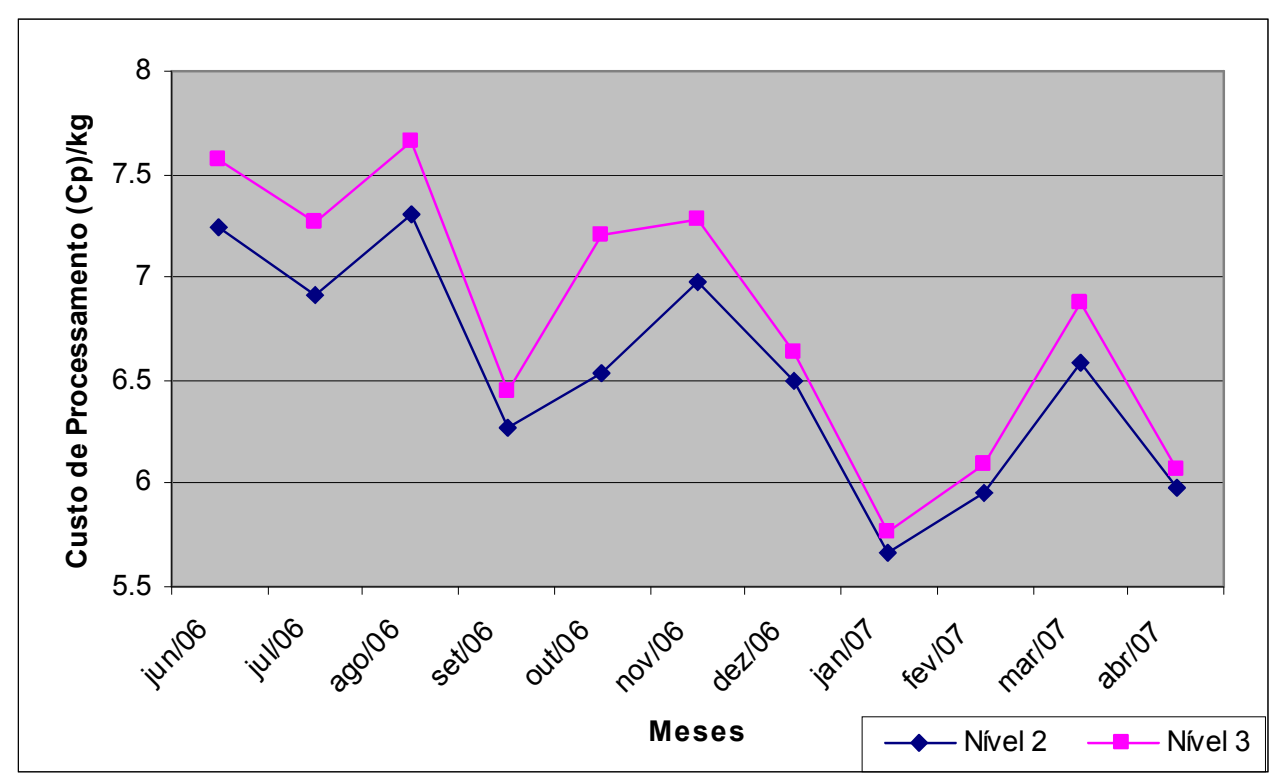

$\mathrm{Ou}$ seja, simulando que nos meses pesquisados a empresa reciclasse internamente seus resíduos sólidos e os adicionasse a composição de carga como lingote secundário, os custos de processo seriam, em todos os meses, mais reduzidos se comparados ao nível 3.

A partir destes percentuais realizou-se a avaliação econômica dos custos de produção neste nível, conforme Tabela 10. 
Tabela 10 - Avaliação econômica - nível 2

\begin{tabular}{ccccc}
\hline & $\begin{array}{c}\text { Custo de } \\
\text { Processamento } \\
(\mathbf{C p}) / \mathbf{k g}\end{array}$ & $\begin{array}{c}\text { Subproduto } \\
\text { reciclagem } \\
\text { interna/kg }\end{array}$ & $\begin{array}{c}\text { Custo total } \\
\text { transporte e } \\
\text { disposição/RS }\end{array}$ & $\begin{array}{c}\text { Custo total de } \\
\text { Produção/R\$ }\end{array}$ \\
\hline O & $\mathbf{P = B * \mathbf { 0 , 3 5 }}$ & $\mathbf{R = P * \mathbf { D }}$ & $\mathbf{S = ( ( \mathbf { A } + \mathbf { M } ) * \mathbf { O } ) + \mathbf { R }}$ \\
\hline $\mathrm{Jun} / 06$ & 7.24 & 27.24 & 16.34 & 5186.21 \\
\hline ago/06 & 6.91 & 25.50 & 15.30 & 5086.55 \\
\hline $\mathrm{set} / 06$ & 7.31 & 49.08 & 29.45 & 7676.80 \\
\hline $\mathrm{out} / 06$ & 6.27 & 71.52 & 42.91 & 10432.80 \\
\hline $\mathrm{nov} / 06$ & 6.53 & 90.77 & 54.46 & 10574.42 \\
\hline $\mathrm{dez} / 06$ & 6.98 & 118.86 & 71.32 & 13579.64 \\
\hline $\mathrm{Jan} / 07$ & 6.50 & 13.03 & 7.82 & 3001.91 \\
\hline $\mathrm{Fev} / 07$ & 5.66 & 21.94 & 13.16 & 3995.99 \\
\hline $\mathrm{mar} / 07$ & 6.95 & 30.72 & 18.43 & 3638.18 \\
\hline $\mathrm{Abr} / 07$ & 5.59 & 42.67 & 25.60 & 3911.59 \\
\hline & & 17.12 & 10.27 & 2598.23 \\
\hline
\end{tabular}

Quanto ao subproduto gerado da reciclagem interna, apresenta baixo valor agregado e deve ser destinado às empresas licenciadas para sua disposição, onerando a empresa.

Para se determinar o custo total empregado pela empresa no nível 2 foram somadas a produção e o material oriunda da reciclagem interna, multiplicados pelo custo de processamento (Cp), calculado através da Equação 3 proposta, somado com o custo de transporte e disposição de resíduos.

Uma comparação dos custos de processamento entre os níveis 3 e 2, pode ser vista na Tabela 11.

Tabela 11 - Comparativo do custo total de produção - nível 3 e 2

\begin{tabular}{|c|c|c|c|}
\hline & $\begin{array}{c}\text { Custo de } \\
\text { Processamento/kg }\end{array}$ & $\begin{array}{c}\text { Custo de } \\
\text { Processamento/kg }\end{array}$ & $\begin{array}{c}\text { Redução } \\
(\%)\end{array}$ \\
\hline & Nível 3 & Nível 2 & \\
\hline jun/06 & 7.57 & 7.24 & 4.56 \\
\hline jul/06 & 7.27 & 6.91 & 5.21 \\
\hline ago/06 & 7.66 & 7.31 & 4.79 \\
\hline set/06 & 6.45 & 6.27 & 2.87 \\
\hline out/06 & 7.20 & 6.53 & 10.26 \\
\hline nov/06 & 7.28 & 6.98 & 4.30 \\
\hline $\mathrm{dez} / 06$ & 6.64 & 6.50 & 2.15 \\
\hline jan/07 & 5.77 & 5.66 & 1.94 \\
\hline fev/07 & 6.09 & 5.95 & 2.35 \\
\hline $\mathrm{mar} / 07$ & 6.88 & 6.59 & 4.40 \\
\hline $\mathrm{abr} / 07$ & 6.07 & 5.98 & 1.51 \\
\hline
\end{tabular}

A migração do nível 3 para o nível 2 representa uma redução dos custos médios de processamento em 3,83\%. Conforme demonstrado através da Tabela 11, esta migração traduz uma elevação da eficiência das matérias-primas em $6,58 \%$, desta forma, há viabilidade financeira para 
migração do nível 3 para o nível 2.

Observa-se que a migração do nível 3 para o nível 2 representa apenas a alteração em uma parte do processo, ou seja, reintroduzindo o alumínio reciclado da escória no processo. No entanto, tipo e custo de matérias-primas, custo unitário de processo, rendimento de processo, reciclabilidade, tempo de fundição, consumo energético, armazenagem, procedimentos de fusão, são algumas variáveis determinantes no custo global de processamento, cabendo ações sistêmicas de melhorias contínuas.

A PmaisL, em seu nível 1 de atuação, indica ações de boas práticas, substituição de matérias-primas, alteração no projeto dos produtos e modificações tecnológicas nos processos, objetivando o aperfeiçoamento contínuo dos processos.

Como resultados obtidos com a aplicação dos instrumentos de coleta de dados, foram observados alguns itens de potenciais de melhorias para o setor de fundição de alumínio secundário.

Uma das ações de melhoria contínua que impactaria diretamente no desempenho organizacional seria a implantação de um sistema gerencial priorizando a política de aquisição, separação e tratamento das fontes de alumínio secundário utilizadas como matérias-primas, pois neste segmento estão concentradas as principais variáveis que influenciam na geração de resíduos sólidos.

Para auxiliar as empresas no gerenciamento de suas matérias-primas, o desenvolvimento de padrões de aquisição obrigaria nos fornecedores a agregar valor ao seu negócio através do fornecimento de matéria-prima em qualidade e quantidade.

Criar um procedimento de fusão com base nas matérias-primas disponíveis impactando diretamente nos rendimentos do processo, pois o tempo de fundição é uma das variáveis que afetam a geração de resíduos de fundição, desta forma, a formulação de um procedimento embasado em conhecimentos técnicos reduziria significativamente o tempo total de fusão.

Conforme evidenciado nesta pesquisa, um dos fatores que afetam a geração de resíduos sólidos de fundição é a presença de componentes nos tratamentos de superfície e pintura dos materiais o que elevam os níveis de oxidação do alumínio. Desta forma, estabelecer protocolos de intenção junto as empresa daquele segmento visando eliminação ou substituição daqueles componentes impactaria diretamente na qualidade de alguns tipos de matérias-primas.

Através desta pesquisa verificou-se que os investimentos do setor de reciclados em tecnologias para elevar o rendimento de materiais secundários com alta contaminação e conjugados são incipientes. Desta forma, sugere-se a reversão deste cenário objetivando maximizar o grau de reciclabilidade dos materiais e consequentemente elevar o rendimentos dos processos.

Além de ações técnicas o estabelecimento de metas voluntárias de desenvolvimento sustentável também impactaria diretamente no desempenho da organização, em relação aos seus 
ativos intangíveis tais como: credibilidade, imagem, reputação e competência.

\section{Conclusão}

Os tipos de matérias-primas utilizadas no processo é apenas um de uma combinação de fatores que influenciam na geração de resíduos sólidos. Desta forma, objetivando complementar as análises acima e auxiliar nas tomadas de decisões para o gerenciamento ambiental utilizou-se os conceitos da PmaisL para avaliar ações através dos dados coletados, analisar as possibilidades técnicas e financeiras de migração para ações mais complexas e sugerir ações de melhoria contínua.

Inicialmente levantaram-se os dados primários de produção, onde verificou-se que o percentual médio de escórias geradas foi de 14,38\%, o custo de transporte e disposição final dos resíduos foi determinado através de cotação com empresas licenciadas à $\mathrm{R} \$ 0,60 / \mathrm{kg}$ e o preço de venda dos resíduos é de $\mathrm{R} \$ 0,80 / \mathrm{kg}$.

Partindo destes dados verificou-se que atualmente a empresa atua no nível 3 de PmaisL onde a totalidade dos resíduos sólidos gerados é comercializada para empresa licenciada para reciclagem externa. No período pesquisado, o nível médio de eficiência das matérias-primas foi de $81,68 \%$ e o custo médio de processamento foi de $\mathrm{R} \$ 6,81 / \mathrm{kg}$.

A partir desta análise avaliaram-se as possibilidades técnicas e financeiras para a empresa migrar para ações mais complexas de gerenciamento ambiental, o nível 2 de PmaisL.

$\mathrm{Na}$ avaliação técnica realizada concluiu se que há possibilidades para migração com ganhos de produtividade na ordem de $6,58 \%$, através da recuperação de $65 \%$ do alumínio metálico contido nas escórias, sem grandes alterações tecnológicas.

Mostrou-se que há possibilidade financeira de migração para o nível 2. Para isto, foi calculado o custo de processamento através de uma expressão que apontou uma redução de 3,83\% em relação ao nível 3.

Do levantamento realizado sugeriram-se ações políticas, tecnológicas e gerenciais de melhorias contínuas para elevar o índice de reciclagem de alumínio para níveis superiores aos atuais $37 \%$.

\footnotetext{
Abstract

The aluminum recycling industry has been growing and demanding adaptations of some management tools to this new segment of the market. Concerning the foundry stage, the management of raw materials is fundamental for the sustainability of this sector, some critical aspects are related to the logistics, availability, costs and quality of secondary sources of aluminum. This management is related to the productivity and profitability of the foundry process, because if has a direct influence in the losses of the process. By researching information concerning the production process of a small industry in the segment of foundry, some data has been acquired, which has aided in the determination of the current organizational scenario in terms of productivity, costs and generation of solid residue. Based on the concept of Cleaner Production, the use of raw
} 
materials and the technical and financial possibilities of migration to more complex actions aiming the increase of efficiency of the process have been analyzed.

Key-words: Secondary aluminum foundry, Cleaner Production, Solid Residue, Processing Costs.

\section{Referências}

ASSOCIAÇÃO BRASILEIRA DO ALUMÍNIO (a). Alumínio para Futuras Gerações: o alumínio nos transportes, 2004.

BENDER, O. W. CRUZ, A. C. da. Reciclagem do alumínio pelo uso de forno plasma: forno piloto IPT. II Congresso Internacional do Alumínio, São Paulo, SP Brasil. Anais, Agosto, 2005.

CENTRO NACIONAL DE TECNOLOGIAS LIMPAS SENAI-RS/UNIDO/INEP. Implementação de programas de Produção mais Limpa. Porto Alegre, 2003. 42p.

CONSELHO EMPRESARIAL BRASILEIRO PARA O DESENVOLVIMENTO SUSTENTÁVEL - Guia da produção mais limpa: faça você mesmo. 2002.

DIAZ, C. A. P. PIRES, S. R. I. Produção mais limpa: integrando meio ambiente e produtividade. RACRE - Rev. Adm. CREUPI, Espírito Santo do Pinhal - SP, v. 05, n. 09, jan/dez. 2005.

ELIAS, S. J. B. e GUIMARÃES, L. C. Contribuição da produção enxuta para a obtenção da produção mais limpa. XXIII Encontro Nacional de Engenharia de Produção - ENEGEP, Outro Preto, MG, Brasil. Anais, ABEPRO, outubro , 2003.

LEMOS, A. D. da C. A Produção mais Limpa como geradora de inovação e competitividade: o caso da fazenda Cerro do Tigre. 1998. 182p. Mestrado em Administração - Universidade Federal do Rio Grande do Sul.

MARINHO, M. e KIPERSTOK A. Ecologia industrial e prevenção da poluição: uma contribuição ao debate regional. Bahia Análise \& Dados. v.10, n.4, p.271-279, março 2001, Salvador - Ba.

\section{Dados dos autores:}

Nome completo: Adriana Gresielly Fabrini Diniz

Filiação institucional: Universidade Tecnológica Federal do Paraná

Departamento: Coordenação de Educação Geral

Função ou cargo ocupado: Professor

Endereço completo para correspondência (bairro, cidade, estado, país e CEP): R. Ernani Batista Rosas - Cj. Monteiro Lobato - B1 30 Apto 16 - cep: 84015-900 - Jardim Carvalho - Ponta Grossa Paraná

Telefones para contato: 42-9124 1202

e-mail:adri.diniz@yahoo.com.br

Nome completo: Ivanir Luis de Oliveira

Filiação institucional: Universidade Tecnológica Federal do Paraná

Departamento: Coordenação de Mecânica

Função ou cargo ocupado: Professor 
Endereço completo para correspondência (bairro, cidade, estado, país e CEP): Av. Monteiro Lobato, s/n - Km 04 - cep: 84016-210 - Ponta Grossa - Paraná

Telefones para contato: $42-32204800$

e-mail:ivanir@pesquisador.cnpg.br

Recebido para publicação em: 02/04/2008

Aceito para publicação em: 05/06/2008 